\title{
Stress profile influences learning approach in a marine fish
}

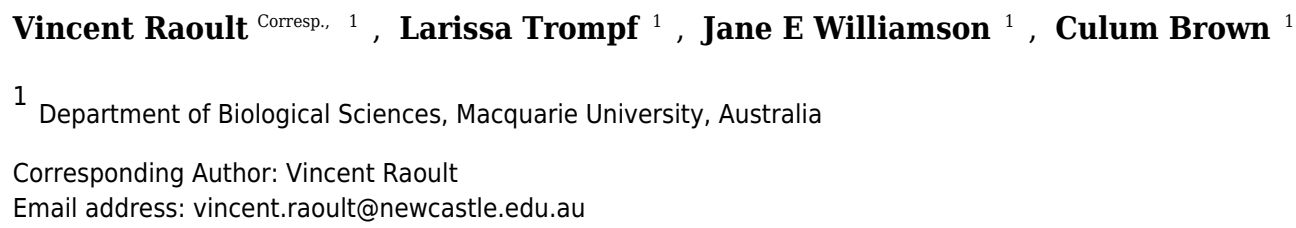

The spatial learning skills of high and low stress juvenile mulloway (Argyrosomus japonicus) were tested in a dichotomous choice apparatus. Groups of fish were formed based on background blood cortisol levels and required to learn the location of a food reward hidden in one of two compartments. Low stress fish characterised by low background levels of the stress hormone cortisol had higher activity levels and entered both rewarded and unrewarded rooms frequently. Within the first week of exposure, however, their preference for the rewarded room increased, indicative of learning. Fish that had high background levels of cortisol, in contrast, showed low levels of activity but when they chose between the two rooms they chose the rewarded room most often but showed less improvement over time. After 12 days in the apparatus, both low and high stress fish had similar ratios of rewarded vs unrewarded room entrances. Our results suggest that proactive coping styles may increase exposure to novel contexts and thus favour faster learning but at the cost of reduced initial accuracy. 


\section{Stress profile influences learning approach in a marine fish}

2

3 Vincent Raoult, Larissa Trompf, Jane E. Williamson, Culum Brown

4 5

\section{Abstract}

7 The spatial learning skills of high and low stress juvenile mulloway (Argyrosomus japonicus)

8 were tested in a dichotomous choice apparatus. Groups of fish were formed based on background

9 blood cortisol levels and required to learn the location of a food reward hidden in one of two compartments. Low stress fish characterised by low background levels of the stress hormone cortisol had higher activity levels and entered both rewarded and unrewarded rooms frequently. Within the first week of exposure, however, their preference for the rewarded room increased, indicative of learning. Fish that had high background levels of cortisol, in contrast, showed low levels of activity but when they chose between the two rooms they chose the rewarded room most often but showed less improvement over time. After 12 days in the apparatus, both low and high stress fish had similar ratios of rewarded vs unrewarded room entrances. Our results suggest that proactive coping styles may increase exposure to novel contexts and thus favour faster learning but at the cost of reduced initial accuracy.

\section{Introduction}

Learning is of key importance to mobile animals existing in heterogeneous environments and influences just about every aspect of their biology (Brown et al., 2011). Factors that affect learning may influence both an animal's ability to learn and/or the way in which it learns, for 
24 example via trade-offs between speed and accuracy (Wang et al., 2015) or through preferences

25 for socially mediated versus private information (Webster et al., 2013). Personality, defined as

consistent differences in behaviour between individuals across time and/or context (Wolf and

Weissing, 2012), is one factor that may drive variability in learning approach. Personality traits such as boldness or shyness have been shown to be correlated to learning ability for a range of taxa (see Griffin et al. (2015)) including fish (Trompf and Brown, 2014, Sneddon, 2003).

Learning plays a key role in fish behaviour in both wild and captive populations (Kieffer and Colgan, 1992, Brown et al., 2011). In an aquaculture context, for example, captive-reared fish may have to learn to anticipate various husbandry related events such as cleaning, or how to interact with self-feeders. Groups of rainbow trout (Oncorhynchus mykiss) took approximately 25 days to learn to use self-feeders and there was considerable individual variation in efficacy (Alanärä, 1996). Historically much of this variation was thought to be explained by hierarchy, but variation in personality plays an underlying role in determining hierarchy (Colléter and Brown, 2011). Thus, much of this variation in captive fish behaviour may also be due to differences in personality. Moreover, research is increasingly directed towards behavioural conditioning of hatchery-reared fish as a mean of diminishing mortality rates post release (Kellison et al., 2000, Fairchild and Howell, 2004, Donadelli et al., 2015, Sloychuk et al., 2016). Much of this conditioning involves learned responses to predators and prey (Brown and Laland, 2011, Brown and Day, 2002). Thus, understanding the link between personality and learning ability has direct applications for fisheries, aquaculture and hatchery management.

The relationship between personality and learning may be mediated in part through an animal's stress physiology (Raoult et al., 2012b, Thomson et al., 2011). Individuals within a species may consistently vary in their behavioural and physiological response to stressful 
47 situations both between and within populations - correlations that have been characterised as

48 coping styles (Koolhaas et al., 1999)(Øverli et al., 2006). Proactive strategies are typified by high

49 levels of activity, including active avoidance of stressful stimuli, and are associated with

50 activation of the sympathetic-adrenomedullary system. Reactive coping styles, in contrast, are

51 generally associated with high levels of passivity and immobility, and activation of the pituitary-

52 adrenocortical system (the hypothalamus-pituitary-interrenal (HPI) axis in teleost fish) (Øverli et

53 al., 2007, Schjolden et al., 2006). Proactive individuals tend to be more reliant on routine than

54 reactive individuals. Reactive individuals, in contrast, show greater behavioural flexibility in

55 response to changes in their environment (Coppens et al., 2010, Mesquita et al., 2015). Stress and

56 divergent coping styles have been linked to memory formation in fish. Rainbow trout selected

57 for low stress responsiveness retained a learned conditioned response for a greater length of time compared to trout selected for high responsiveness (Moreira et al., 2004). Moreover, Barreto et al. (2006) found that treating rainbow trout with cortisol-releasing implants impaired their memory processes. While a low stress response may be advantageous in an aquaculture setting (Huntingford and Adams, 2005, Huntingford et al., 2010), associated behavioural characteristics such as boldness may enhance learning. found along the eastern and southern shores of Australia. This species can grow to over $40 \mathrm{~kg}$ and is an aggressive predatory fish that is popular with game fishermen. Due to the species' rapid rate of growth, it is being considered for potential as an aquaculture species for both re-stocking and commercial uses in Australia (Fielder et al., 1999, Guy et al., 2014). Links between boldness and blood cortisol concentrations in this species have been shown previously (Raoult et al., 2012b) but the relationship between personality and learning ability has yet to be investigated. 
70 Here we compared the learning ability of shy, high stress and bold, low stress juvenile mulloway

71 in a simple spatial learning task where a food reward was hidden in one of two compartments.

72 We predicted that bolder, low stress individuals should be faster to learn novel tasks than shy,

73 high stress individuals. We also predicted that bolder fish may initially show higher levels of 74 inaccuracy relative to shy fish.

75

76

77

78

79

80

81

82

\section{Materials and methods}

Juvenile mulloway $(\mathrm{n}=150)$ were obtained from aquaculture pens in Botany Bay, Australia, and transported to the experimental facilities in Cronulla's Fisheries Research Centre (CFRC) in Sydney. Subjects (369 $\pm 13 \mathrm{~mm}$ length; $495 \pm 48.5 \mathrm{~g}$ weight) were derived from the same spawning event with multiple parents, originating from brood stock collected from Botany Bay. These fish were the same individuals used in Raoult et al. (2012b).

Fish were housed in an outdoor 5000L flow-through tank taking water from the adjacent bay, thus water temperature varied seasonally (mean of $14^{\circ} \mathrm{C}$ ) and the tank was exposed to natural variations in diurnal light and temperature. Individuals were fed $\sim 2 \%$ of their weight in $0.5 \mathrm{~mm}$ commercial pellet feed daily.

\section{Pit tags and blood sampling}

One month following transfer to experimental facilities, mulloway were anaesthetised in a light solution of AQUI-S (5ml/1000L), gently netted from their housing tank using a soft mesh net, placed in a secondary surgical anaesthesia bath in an AQUI-S solution (10ml/1000L) until 
93 they lost their buoyancy control, held with a wet towel, and fitted with Passive Integrated

94 Transponder tags (PIT) as outlined in (Raoult et al., 2012a). Trovan ID100 tags (2.2x11mm)

95 were implanted via sterile needle inserters in the body cavity posterior to the pectoral fins.

96 Simultaneously, blood was collected from the caudal vein (1-2ml) for cortisol analysis. Resulting

97 incisions were sealed using superglue to aid in tag retention and reduce haemorrhaging (Raoult et

98 al., 2012a). Each fish was placed in a highly aerated 100L tank for post-handling recovery.

99 Fresh seawater was then flushed through their gills using a low-pressure hose and the fish was

100 monitored until recovery. The entire process from capture to recovery took less than 5 min per

101 fish. The netting process caused minimal disturbance to the rest of the fish in the holding tank,

102 although there was a slight increase in baseline cortisol levels over the tagging period which we

103 controlled for statistically (see Raoult et al., 2012b). Tagging incisions fully healed in the first 104 week.

Stress levels were determined by obtaining background blood cortisol levels from blood samples taken shortly after pit tagging. Note the tagging procedure was too rapid for the fish to mount a blood cortisol response and thus the levels detected reflect pre-existing variation in the population, for example through individual position in the hierarchy. Background blood cortisol

levels were of interest as they likely represent natural conditions similar to those fish experienced

110 in the housing tanks and during learning trials. We could not determine cortisol concentrations

111 from water samples (Scott and Ellis, 2007, Zuberi et al., 2011) due to limitations in the aquaria

112 facilities and the number of fish housed in the system. Blood samples were analysed for cortisol 113 concentrations with a coat-a-count kit from Diagnostic Products Corporation (Los Angeles, CA, 114 USA) (refer to (Raoult et al., 2012b) for further details). There was a positive relationship 115 between sampling order and measured cortisol levels, however, this relationship only explained 
$1166 \%$ of the variation, and a subsequent ANCOVA taking into account sampling order found no

117 relationship between sampling order and stress type, suggesting that our cortisol assays were

118 accurate assessments of fish background stress levels (Raoult et al. (2012b). Fish blood cortisol

119 concentrations above the median blood cortisol concentration $(110 \mathrm{ng} / \mathrm{mL})$ were labelled as

120 "high stress fish" (mean cortisol concentration of $261.7 \pm 22.25 \mathrm{ng} / \mathrm{ml}$ ) and those with

121 concentrations below the median were labelled as "low stress fish" (mean cortisol concentration

122 of $43.9 \pm 9.04 \mathrm{ng} / \mathrm{ml}$; Fig. 1). Eighteen low stress and eighteen high stress subjects were selected

123 from either end of this distribution to take part in the learning trial (Fig. 1).

124 As growth rates are known to vary with coping style (Biro et al., 2006, Øverli et al.,

125 2007), different growth rates over the lives of these aquaculture-grown mulloway could have

126 resulted in size differences between low and high stress individuals, which would also lead to

127 lower foraging activity (Polverino et al., 2016). However, the fish were all the same age and

128 there was no significant correlation between body weight and cortisol concentration $\left(F_{1,76}=2.34\right.$,

$129 p>0.05)$, and due to the relatively short duration of the study ( $<3$ months) it was unlikely that

130 growth rate of individuals influenced these experiments. Note, we made no attempt to quantify

131 growth rate during the brief study period.

132 No mortalities were recorded during the study, from their retrieval in the aquaculture

133 pens to the conclusion of research. Fish were retained in the aquarium facilities at CFRC

134 following the end of the project. This research was conducted under Macquarie University

135 Animal Ethics and Care approval number 2009/008.

136

137 Learning test 

required the fish to locate a food reward in one of two compartments. The experimental arena used for the learning task consisted of a large circular tub $(2.4 \varnothing, 1.2 \mathrm{~m}$ deep $)$ divided into three

141 compartments using $2 \mathrm{~mm}$ thick opaque plastic sheets. Two smaller compartments were of equal

142 size (ca $1 / 4$ of the arena) and connected to the third large compartment (ca $1 / 2$ the arena) via $27 \mathrm{~cm}$

143 circular doorways cut into the plastic dividers just below the water level (Fig. 2a, 2b). A false

144 floor was created using breathable plastic weed mats in the two smaller compartments to reduce

145 the depth to $40 \mathrm{~cm}$. This encouraged the fish to enter the compartment and return to the larger, 146 deeper compartment once they had finished eating. Pilot studies showed that these fish had a 147 clear preference for the deeper compartment. The entrances to the small compartments were 148 fitted with an ANT C270 antenna. LID650 PIT tag readers were attached to the antennae to 149 record the time that individuals passed from one compartment to another. Preliminary tests 150 conducted with the PIT tags alone verified that the readers would only record a tag when it was 151 within the circular antenna.

An auto feeder (Eheim) was mounted above one of the small compartments and deposited feed at a set time each day as described below. Remaining food particles were siphoned off every morning. An inlet pipe was placed in each of the small compartments to maintain a high flow of water $\left(10 \mathrm{~L} \cdot \mathrm{min}^{-1}\right.$ each) through the system. The large compartment that housed the overflow and air stones was placed directly opposite the other two compartments.

Fish were tested in groups because $A$. japonicus does not respond well to social isolation 158 (Pirozzi et al., 2009). Six groups of six low or high stress individuals were tested (three groups of each stress type; $\mathrm{n}=36$ fish in total). While measuring the behaviour of groups with similar stress characteristics could have led to an exaggeration of low-stress and high-stress response 
161 behaviours, this was preferable to mixing stress types, which could result in negative interactions

162 between low-stress and high-stress individuals within groups that could dampen both

163 behavioural types. Using mixed stress type groups would be more similar to natural conditions

164 (Verbeek et al., 2008), while groups with a homogenous stress type would resemble aquaculture

165 breeding conditions (Castanheira et al., 2015). Individuals were gently netted from their home

166 tank, identified by their PIT tag and placed in the experimental tank for a $24 \mathrm{~h}$ acclimation

167 period. Data recording began thereafter. As mulloway are reportedly largely nocturnal, the shoals

168 were fed via the automatic feeders four times nightly (1900, 2200, 0100, 0400h) with rations of

$1690.25 \%$ of their collective body. Trials were run for three weeks or until 2000 PIT tag recordings

170 were made for each experimental shoal, whichever occurred sooner. The 2000 recording limit

171 was chosen to ensure that the on-board memory of the recording apparatus would be sufficient to 172 record all data.

174 Analysis

175 The number of detections at the entrance to each of the small compartments was used to 176 quantify the number of visits each fish made to each compartment each day. The data were

177 analysed in three main ways. Firstly, we examined the change in global activity levels by

178 examining the number of daily visits to both compartments for every fish over the length of the

179 experiment. We also examined the change in the number of visits to the rewarded and

180 unrewarded compartments separately. Our expectation was that low stress fish would be more

181 active than high stress fish, but high stress fish might gradually habituate to the test area and

182 thereby increase their activity levels. Secondly, we determined if low and high stress fish showed

183 significant differences in the number of detections between the rewarded and unrewarded 
184 compartments over time. That is, did the fish develop a preference for the rewarded location and

185 make fewer errors by avoiding the unrewarded location. The expectation was that fish would

186 initially choose a compartment at random but would gradually learn which compartment

187 contained the food reward. We hypothesised that low stress fish might show faster learning

188 because their high activity levels lead them to rapidly explore the test arena. The total number of

189 entrances into the rewarded compartment for each fish each day was log-transformed prior to

190 analysis in all cases. The final analysis examined the ratio of detections in the rewarded vs

191 unrewarded compartments for each individual each day. This analysis controlled for differences

192 in total activity of the two groups of fish. If the fish learnt the location of the food reward, we

193 expected the ratio of rewarded vs unrewarded compartment entries to increase over time. The

194 resulting number between 0 and 1 was then adjusted by 0.5 so that a value of 0.5 indicated no

195 preference for either compartment.

Data were analysed using general linear mixed models using groups as a random variable

197

198

199

200

201

202

203

204

205

206 and stress status (high or low cortisol values) as a fixed variable. We employed a repeated

measures approach with day number as the repeated measure. Data were analysed using $\mathrm{R}$

version 3.3.2 and the lme4 package. A restricted likelihood ratio test (RLRT) was used to

determine whether the random factor group had an effect with the RLRsim package. Preference

results were transformed using a logit transformation, and numbers of recordings were $\log +1$

transformed. Interaction effects between day and stress type were measured for recording models

to record differences in activity over time, but not for preference models since preference levels

should start and end at similar optimums for both treatments (start with no preference for either

compartment and end with similar 'learnt' preference). In addition, adding an interaction did not improve the preference model. 


\section{Results}

As expected, our observations suggested that fish did not spend much time in the small compartments. Fish generally entered the smaller compartments and then rapidly returned to the larger compartment. Despite being tested in groups, there was still a high degree of individual variation within each group, suggesting that that the presence of other fish with similar stress profiles did not exacerbate or dampen stress-driven behaviours, and that the results from this study could largely be interpreted on an individual level. However, the random factor (group ID) varied significantly for both models (RLRT analysis $P>0.05$ ). This effect was likely due to the idiosyncratic behaviour of individuals in small groups, and thus generalized linear models were run without group as a random factor. Tag detections showed no peak activity time indicating that, contrary to expectations, fish entered the compartments consistently throughout the day and night.

The number of recordings per day increased over time, suggesting that the fish became

221

222

223

224

225

comfortable with exploring the compartments (Table 1; Figs 3). Low stress fish entered both compartments significantly more often than high stress fish (Table 1; Fig 3), which is indicative of higher activity levels over the entire experimental period. Both groups of fish had higher detections for the rewarded compartment overall, suggesting a general preference for the rewarded compartment over the experimental period. There was a significant interaction between day and stress type, indicating that the number of recordings for low stress fish increased faster than high stress fish.

Preference for the reward compartment increased significantly for both treatments over the duration of the experiment, suggesting fish learnt where the reward compartment was (Table 
2302 ; Fig 4). Low stress fish had a significantly higher preference for the reward compartment over

231 the duration of the experiment, though both stress types started and ended at similar levels of

232 preference. Low stress fish achieved their maximum preference at $\sim 7$ days, whereas high

233 responding fish took 12 days to reach a similar level.

234

235 Discussion

236 Our results show that fish with high and low levels of background cortisol had different

237 approaches to the learning task. Low stress fish had much higher levels of activity and entered

238 the rewarded compartment in the simple maze more frequently than high stress fish. Moreover,

239

the preference for the reward room over the unrewarded room showed that low stress fish

240 initially had similar preference as high stress fish but rapidly improved, especially over the first

241 week of the experiment. This suggests that the high activity levels of these fish were tempered by

242 poor accuracy, but they eventually learned the location of the food reward as a result of their pro-

243 active coping style. In contrast, high stress fish had lower levels of activity than low stress fish

244 and rarely entered compartments, but when they did so it was most often the one containing the

245 food reward. Interestingly, their preference was similar to low stress fish to begin with but did

246 not improve to the same extent as low stress fish, which is reminiscent of reactive coping styles

247 (Koolhaas et al., 1999). While both groups attained the same level of performance by the end of

248 the experimental period (day twelve), they arrived at this point at different speeds.

249 Our results echo work focussing on boldness-accuracy trade-offs (Mamuneas et al.,

250 2014). The generally higher levels of activity in our low stress fish enabled them to rapidly

251 explore their environment, placing them in novel contexts and increasing the likelihood of

252 performing innovative behaviours (Schjolden et al., 2006). However, this behaviour was offset 
253 by the fact that they seemed to pay little attention to appropriate cues and initially suffered from

254 low accuracy, similar to patterns observed in rainbow trout during a reversal task (Ruiz-Gomez

255 et al., 2011). High stress fish, by contrast, paid more attention to environmental cues and had a

256 similar initial preference despite lower activity levels.

257 Assessing stress in this instance required the use of a method approved by an Australian

258 animal ethics committee, as blood samples need to be extracted and a PIT tag implanted into

259 large and powerful fish, a process that, without anaesthesia, would likely be excessively painful

260 for the animals and difficult for handlers. AQUI-S is a widely-used clove oil concentrate that is

261 effective at incapacitating fish in aquaculture environments while being safe for human

262 consumption. It is possible that the use of such an anaesthetic could interfere with the stress

263 response, however, the use of AQUI-S in A. regius, a close relative of $A$. japonicus, revealed that

264 AQUI-S either had no effect on blood plasma cortisol concentrations (Barata et al., 2016), or

265 doubled blood plasma cortisol concentrations relative to a control group from 20 to $40 \mathrm{ng} / \mathrm{ml}$

266 (Cárdenas et al., 2016). Our previous work identified a positive relationship between sampling

267 order and cortisol blood concentration when subjects were maintained in low concentrations of

268 anaesthetic prior to sampling, but this only explained $6 \%$ of the variation (Raoult et al 2012b).

269 Our data suggest that exposure to low concentrations of AQUI-S had little impact on the cortisol

270 levels in this species.

271 The range of blood cortisol concentrations we detected in A. japonicus (10-600ng/ml)

272 appears to be large. No comparable study exists to examine whether this range is surprising or

273 typical for this species. Studies that examined blood cortisol concentrations in a species from the

274 same genus (A. regius) found maximum concentrations of $\sim 40 \mathrm{ng} / \mathrm{ml}$ post mortem (Millán-

275 Cubillo et al., 2016) or $269 \mathrm{ng} / \mathrm{ml}$ after exposure to clove oil (Cárdenas et al., 2016). The 
276 Cárdenas et al. (2016) study is the most comparable, both in terms of experimental treatment and

277 the range of values observed. Note, however, that in Cárdenas et al. (2016) fish were lightly

278 anesthetised using clove oil and placed in fresh seawater for 30 minutes prior to the blood sample

279 be taken. Their fish were also substantially smaller than ours (136 $\pm 9 \mathrm{~g}$ compared to $495 \pm$

$28048.5 \mathrm{~g}$ ). Larger fishes are known to produce larger stress responses than smaller individuals

281 (Fatira et al., 2014). Future studies should attempt to gauge the scale and speed of blood cortisol

282 responses in A. japonicus following a stressor and examine some of the potential causes for the

283 range of background stress levels (eg hierarchies; Colleter and Brown, 2011).

Populations of fish bred in captive conditions generally have behavior that is skewed

285

286

287

288

289

290

291

292

293

294

295

296

297

towards the bold/low stress side of the behavioral spectrum (Sundström et al., 2004, Kelley et al., 2006). The subjects used herein were bred from wild broodstock, which may explain the wide variation in coping styles observed between individuals. One would expect such variation to be eroded over time through artificial selection given that these physiological traits are known to be heritable (Benus et al., 1991, Koolhaas et al., 2010). It should thus be feasible to selectively manage coping styles in an aquaculture context if desired, but one must be mindful of altering non-target behavior in the process. Other studies have affected the plasma cortisol responses of a cultured fish (rainbow trout) through selective breeding (Pottinger and Carrick, 1999), and it should be possible in other species of fishes (Pottinger and Pickering, 2011). One might manage the selection regime depending on whether the fish were destined to be released in the wild or destined for the dinner plate. The presence of a syndrome between activity levels, stress responses, personality and coping styles, however, begs the question as to whether any given trait could be selected individually. 
Our study, combined with our previous work linking boldness and stress in this

299

300

301

302

303

304

305

306

307

308

309

310

311

312

313

314

315

316

317

318

319

320

population (Raoult et al., 2012b), suggests that differences in coping style and personality can have significant influences on cognitive function and information use in aquaculture species (Moreira et al. (2004), Barreto et al. (2006), Carter et al., 2013; Kurvers et al., 2010). Mechanistically, this could be explained by findings that corticosteroids at lower levels have a permissive effect on learning but chronic stress and high levels of circulating cortisol appear to impair memory (Roozendaal, 2002). It may also be that animals with different coping styles employ different learning strategies, for example preferring associative learning over systematic search patterns or vice versa (Mesquita et al., 2015). Such differences might explain variation in how fish respond to novelty in an aquaculture setting, for example, in the manner in which they interact with self-feeders (Alanärä, 1996) or respond to regular cleaning (Huntingford and Adams, 2005). Rapid variation in growth and condition often accumulate in aquaculture populations in the absence of regular sorting and it may well be that much of this variation might be related to the coping strategies employed by particular individuals. Lastly, it might be possible to behaviourally type a species or population before bringing it into an intensive aquaculture setting, provided the user is aware of the costs and benefits that are associated with their choice (Biro et al., 2010, Benus et al., 1991). Such a screening could predict how the species would respond to life in captivity.

In conclusion, our study shows an association between learning approach, personality and stress responsiveness in a marine fish and has highlighted the effects that coping styles can have on the interaction between marine fish and their captive environment. We suggest that both low and high stress phenotypes may be selected for in different contexts and may explain the wide variation observed in natural populations. Animals with a more cautious phenotype and high 
321 stress, reactive coping styles with a concomitant greater degree of phenotypic plasticity may be

322 selected for in highly variable environments (for example release into the wild), whereas low

323 stress, proactive fish may have better outcomes in more stable environments such as those in

324 intensive aquaculture (Koolhaas et al., 2010, Cockrem, 2013).

\section{Acknowledgements}

327 The facilities were graciously provided by NSW Department of Industry and Investment's

Fisheries Research Centre at Cronulla, Sydney. Thanks especially to Dave Barker for all his

329 help.

\section{References}

333

334

335

336

ALANÄRÄ, A. 1996. The use of self-feeders in rainbow trout (Oncorhynchus mykiss) production. Aquaculture, 145, 1-20.

BARATA, M., SOARES, F., ARAGÃO, C., ALMEIDA, A. C., POUSÃO-FERREIRA, P. \& RIBEIRO, L. 2016. Efficiency of 2-phenoxyethanol and Clove Oil for Reducing Handling Stress in Reared Meagre, Argyrosomus regius (Pisces: Sciaenidae). Journal of the World Aquaculture Society, 47, 82-92.

BARRETO, R. E., VOLPATO, G. L. \& POTTINGER, T. G. 2006. The effect of elevated blood cortisol levels on the extinction of a conditioned stress response in rainbow trout. Hormones and Behavior, 50, 484-488.

BENUS, R., BOHUS, B., KOOLHAAS, J. \& VAN OORTMERSSEN, G. 1991. Heritable variation for aggression as a reflection of individual coping strategies. Experientia, 47, 1008-1019.

BIRO, P. A., ABRAHAMS, M. V., POST, J. R. \& PARKINSON, E. A. 2006. Behavioural trade-offs between growth and mortality explain evolution of submaximal growth rates. Journal of Animal Ecology, 75, 1165-1171.

BIRO, P. A., BECKMANN, C. \& STAMPS, J. A. 2010. Small within-day increases in temperature affects boldness and alters personality in coral reef fish. Proceedings of the Royal Society of London B: Biological Sciences, 277, 71-77.

BROWN, C. \& DAY, R. L. 2002. The future of stock enhancements: lessons for hatchery practice from conservation biology. Fish and Fisheries, 3, 79-94.

BROWN, C. \& LALAND, K. 2011. Social learning in fishes. In: BROWN, C., LALAND, K. \& KRAUSE, J. (eds.) Fish Cognition and Behavior. Oxford, UK: Wiley-Blackwell.

BROWN, C., LALAND, K. \& KRAUSE, J. (eds.) 2011. Fish Cognition and Behaviour, Oxford, UK: WileyBlackwell.

CÁRDENAS, C., TONI, C., MARTOS-SITCHA, J., CÁRDENAS, S., HERAS, V., BALDISSEROTTO, B., HEINZMANN, B., VÁZQUEZ, R. \& MANCERA, J. 2016. Effects of clove oil, essential oil of Lippia 
alba and 2-phe anaesthesia on juvenile meagre, Argyrosomus regius (Asso, 1801). Journal of Applied Ichthyology, 32, 693-700.

CASTANHEIRA, M. F., CONCEIÇÃO, L. E., MILLOT, S., REY, S., BÉGOUT, M. L., DAMSGAARD, B., KRISTIANSEN, T., HÖGLUND, E., ØVERLI, Ø. \& MARTINS, C. I. 2015. Coping styles in farmed fish: consequences for aquaculture. Reviews in Aquaculture.

COCKREM, J. F. 2013. Individual variation in glucocorticoid stress responses in animals. General and Comparative Endocrinology, 181, 45-58.

COLLÉTER, M. \& BROWN, C. 2011. Personality traits predict hierarchy rank in male rainbowfish social groups. Animal Behaviour, 81, 1231-1237.

COPPENS, C. M., DE BOER, S. F. \& KOOLHAAS, J. M. 2010. Coping styles and behavioural flexibility: towards underlying mechanisms. Philosophical Transactions of the Royal Society B: Biological Sciences, 365, 4021-4028.

DONADELLI, V., LONGOBARDI, A., FINOIA, M. G. \& MARINO, G. 2015. Feeding hatchery-reared dusky grouper Epinephelus marginatus juveniles on live prey: implications for restocking. Environmental Biology of Fishes, 98, 1757-1766.

FAIRCHILD, E. A. \& HOWELL, W. H. 2004. Factors affecting the post-release survival of cultured juvenile Pseudopleuronectes americanus. Journal of Fish Biology, 65, 69-87.

FATIRA, E., PAPANDROULAKIS, N. \& PAVLIDIS, M. 2014. Diel changes in plasma cortisol and effects of size and stress duration on the cortisol response in European sea bass (Dicentrarchus labrax). Fish physiology and biochemistry, 40, 911-919.

FIELDER, D. S., ALLAN, G. L. \& BARDSLEY, W. J. 1999. Enhancement of mulloway (Argyrosomus japonicus) in intermittently opening lagoons. NSW Fisheries, Australia.

GRIFFIN, A. S., GUILLETTE, L. M. \& HEALY, S. D. 2015. Cognition and personality: an analysis of an emerging field. Trends in Ecology \& Evolution, 30, 207-214.

GUY, J. A., MCILGORM, A. \& WATERMAN, P. 2014. Aquaculture in Regional Australia: Responding to trade externalities. A Northern NSW case study. Journal of Economic \& Social Policy, 16, 115.

HUNTINGFORD, F. \& ADAMS, C. 2005. Behavioural syndromes in farmed fish: implications for production and welfare. Behaviour, 142, 1207-1221.

HUNTINGFORD, F. A., ANDREW, G., MACKENZIE, S., MORERA, D., COYLE, S. M., PILARCZYK, M. \& KADRI, S. 2010. Coping strategies in a strongly schooling fish, the common carp Cyprinus carpio. Journal of Fish Biology, 76, 1576-1591.

KELLEY, J., MAGURRAN, A. \& GARCÍA, C. M. 2006. Captive breeding promotes aggression in an endangered Mexican fish. Biological Conservation, 133, 169-177.

KELLISON, G. T., EGGLESTON, D. B. \& BURKE, J. S. 2000. Comparative behaviour and survival of hatcheryreared versus wild summer flounder (Paralichthys dentatus). Canadian Journal of Fisheries and Aquatic Sciences, 57, 1870-1877.

KIEFFER, J. D. \& COLGAN, P. W. 1992. The role of learning in fish behaviour. Reviews in Fish Biology and Fisheries, 2, 125-143.

KOOLHAAS, J. M., DE BOER, S. F., COPPENS, C. M. \& BUWALDA, B. 2010. Neuroendocrinology of coping styles: Towards understanding the biology of individual variation. Frontiers in Neuroendocrinology, 31, 307-321.

KOOLHAAS, J. M., KORTE, S. M., DE BOER, S. F., VAN DER VEGT, B. J., VAN REENEN, C. G., HOPSTER, H., DE JONG, I. C., RUIS, M. A. W. \& BLOKHUIS, H. J. 1999. Coping styles in animals: current status in behavior and stress-physiology. Neuroscience \& Biobehavioral Reviews, 23, 925-935.

MAMUNEAS, D., SPENCE, A. J., MANICA, A. \& KING, A. J. 2014. Bolder stickleback fish make faster decisions, but they are not less accurate. Behavioral Ecology, aru160.

MESQUITA, F. O., BORCATO, F. L. \& HUNTINGFORD, F. A. 2015. Cue-based and algorithmic learning in common carp: A possible link to stress coping style. Behavioural Processes, 115, 25-29. 
405

406

407

408

409

410

411

412

413

414

415

416

417

418

419

420

421

422

423

424

425

426

427

428

429

430

431

432

433

434

435

436

437

438

439

440

441

442

443

444

445

446

447

448

449

450

451

MILLÁN-CUBILLO, A. F., MARTOS-SITCHA, J. A., RUIZ-JARABO, I., CÁRDENAS, S. \& MANCERA, J. M. 2016. Low stocking density negatively affects growth, metabolism and stress pathways in juvenile specimens of meagre (Argyrosomus regius, Asso 1801). Aquaculture, 451, 87-92.

MOREIRA, P. S. A., PULMAN, K. G. T. \& POTTINGER, T. G. 2004. Extinction of a conditioned response in rainbow trout selected for high or low responsiveness to stress. Hormones and Behavior, 46, 450-457.

$\varnothing$ VERLI, $\varnothing .$, S $\varnothing$ RENSEN, C. \& NILSSON, G. E. 2006. Behavioral indicators of stress-coping style in rainbow trout: Do males and females react differently to novelty? Physiology \& Behavior, 87, 506-512.

$\varnothing$ VERLI, Ø., SØRENSEN, C., PULMAN, K. G. T., POTTINGER, T. G., KORZAN, W., SUMMERS, C. H. \& NILSSON, G. E. 2007. Evolutionary background for stress-coping styles: Relationships between physiological, behavioral, and cognitive traits in non-mammalian vertebrates. Neuroscience \& Biobehavioral Reviews, 31, 396-412.

PIROZZI, I., BOOTH, M. A. \& PANKHURST, P. M. 2009. The effect of stocking density and repeated handling on the growth of juvenile mulloway, Argyrosomus japonicus (Temminck \& Schlegel 1843). Aquaculture International, 17, 199-205.

POLVERINO, G., BIERBACH, D., KILLEN, S., UUSI-HEIKKILÄ, S. \& ARLINGHAUS, R. 2016. Body length rather than routine metabolic rate and body condition correlates with activity and risk-taking in juvenile zebrafish Danio rerio. Journal of fish biology, 89, 2251-2267.

POTTINGER, T. \& CARRICK, T. 1999. Modification of the plasma cortisol response to stress in rainbow trout by selective breeding. General and comparative endocrinology, 116, 122-132.

POTTINGER, T. \& PICKERING, A. 2011. Genetic basis to the stress response: selective breeding for stresstolerant fish.

RAOULT, V., BROWN, C. \& WILLIAMSON, J. E. 2012a. Superglue is not super: an assessment of superglue for suturing tag incisions in a cultured marine fish. Journal of the World Aquaculture Society, 43, 140-143.

RAOULT, V., BROWN, C., ZUBERI, A. \& WILLIAMSON, J. E. 2012b. Blood cortisol concentrations predict boldness in juvenile mulloway (Argyosomus japonicus). Journal of Ethology, 30, 225-232.

ROOZENDAAL, B. 2002. Stress and Memory: Opposing Effects of Glucocorticoids on Memory Consolidation and Memory Retrieval. Neurobiology of Learning and Memory, 78, 578-595.

RUIZ-GOMEZ, M. D. L., HUNTINGFORD, F. A., ØVERLI, Ø., THÖRNQVIST, P.-O. \& HÖGLUND, E. 2011. Response to environmental change in rainbow trout selected for divergent stress coping styles. Physiology \& Behavior, 102, 317-322.

SCHJOLDEN, J., PULMAN, K. G. T., METCALFE, N. B. \& WINBERG, S. 2006. Divergence in locomotor activity between two strains of rainbow trout Oncorhynchus mykiss with contrasting stress responsiveness. Journal of Fish Biology, 68, 920-924.

SCOTT, A. P. \& ELLIS, T. 2007. Measurement of fish steroids in water-a review. General and comparative endocrinology, 153, 392-400.

SLOYCHUK, J. R., CHIVERS, D. P. \& FERRARI, M. C. 2016. Juvenile Lake Sturgeon Go To School: Life-Skills Training for Hatchery Fish. Transactions of the American Fisheries Society, 145, 287-294.

SNEDDON, L. U. 2003. The bold and the shy: individual differences in rainbow trout. Journal of Fish Biology, 62, 971-975.

SUNDSTRÖM, L. F., PETERSSON, E., HÖJESJÖ, J., JOHNSSON, J. I. \& JÄRVI, T. 2004. Hatchery selection promotes boldness in newly hatched brown trout (Salmo trutta): implications for dominance. Behavioral Ecology, 15, 192-198.

THOMSON, J. S., WATTS, P. C., POTTINGER, T. G. \& SNEDDON, L. U. 2011. Physiological and genetic correlates of boldness: characterising the mechanisms of behavioural variation in rainbow trout, Oncorhynchus mykiss. Hormones and behavior, 59, 67-74. 
452 TROMPF, L. \& BROWN, C. 2014. Personality affects learning and trade-offs between private and social information in guppies, Poecilia reticulata. Animal Behaviour, 88, 99-106.

454 VERBEEK, P., IWAMOTO, T. \& MURAKAMI, N. 2008. Variable stress-responsiveness in wild type and 455 domesticated fighting fish. Physiology \& behavior, 93, 83-88.

456 individually consistent decision making by individuals and dyads of zebrafish in a colour discrimination task. Animal Behaviour, 103, 277-283.

WEBSTER, M. M., ATTON, N., HOPPITT, W. J. \& LALAND, K. N. 2013. Environmental complexity influences association network structure and network-based diffusion of foraging information in fish shoals. The American Naturalist, 181, 235-244.

WOLF, M. \& WEISSING, F. J. 2012. Animal personalities: consequences for ecology and evolution. Trends in Ecology and Evolution, 27, 452-461.

464

465 


\section{Figure 1 (on next page)}

Ranked blood cortisol concentrations measured for entire sampled population of mulloway in this study.

Low-stress and high-stress fish used in this study are indicated with squares or diamonds, the remainder of the population is marked with Xs. Fish were separated into low-stress and highstress depending on whether they were below or above the median blood cortisol concentration (110ng/ml). 


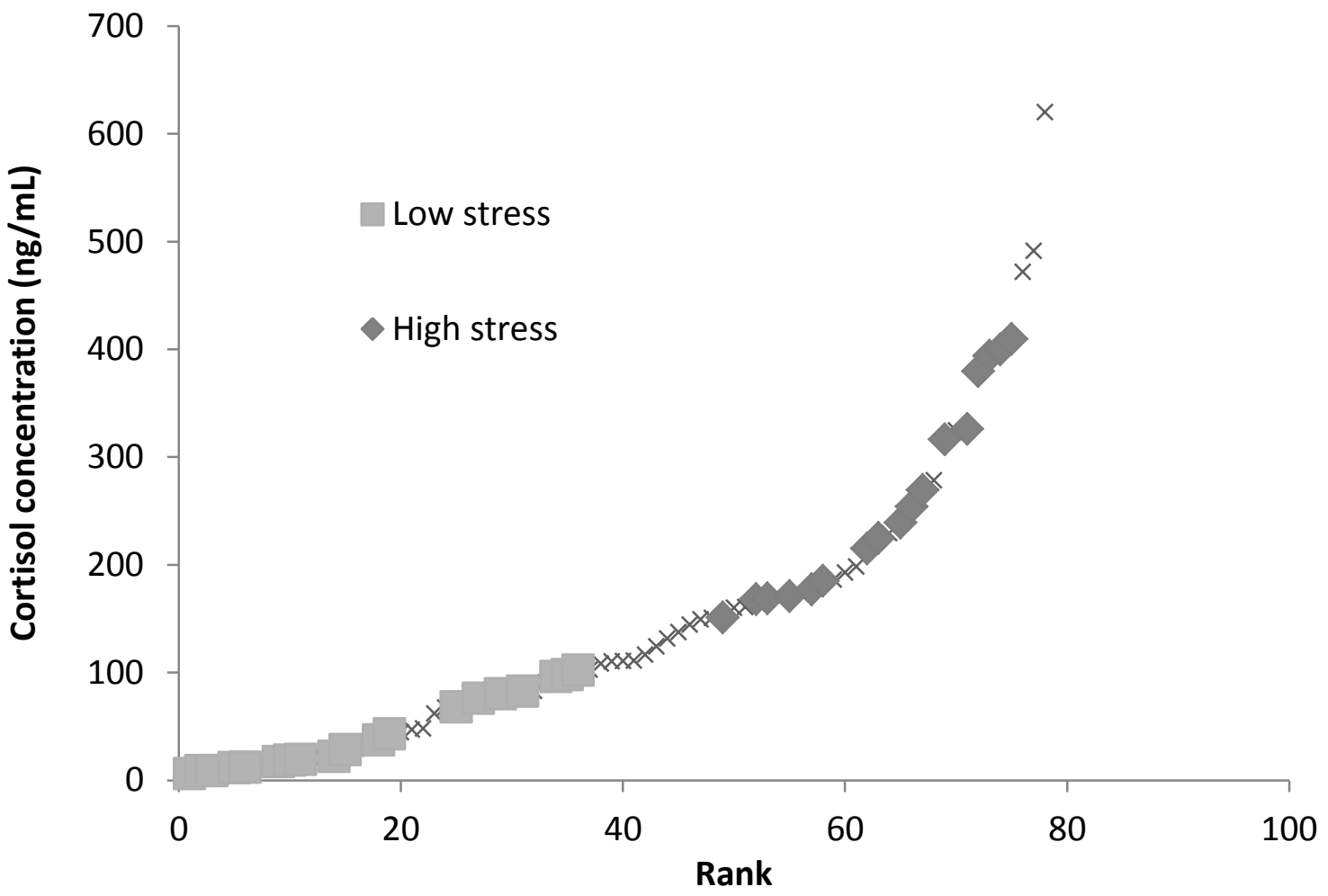


Figure 2

Schematic a) top view and b) side view of experimental tank used for learning experiments.

The learning experiment tank was a $2.4 \mathrm{~m}$ diameter and $1.2 \mathrm{~m}$ high flow-through system. The presence of PIT tag recorders at the entries of the rewarded and unrewarded compartments allowed a measure of activity into and out of those compartments for each individual fish.

A)

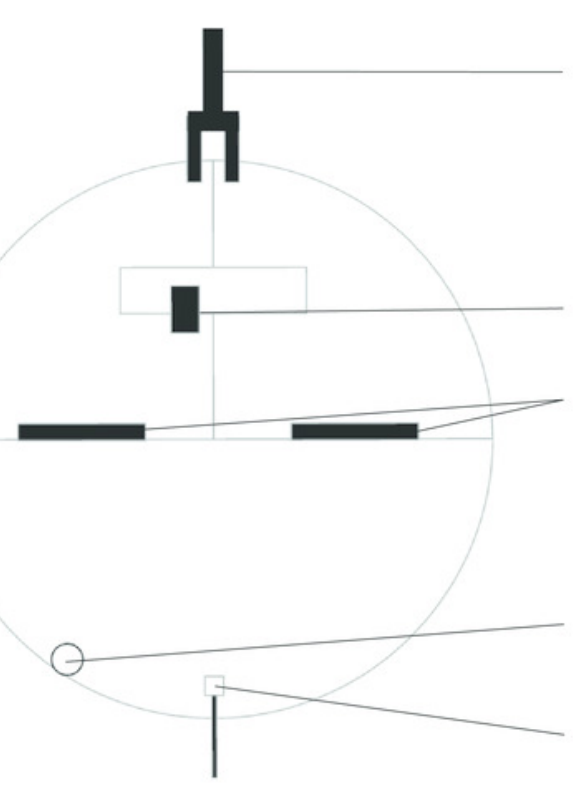

B)

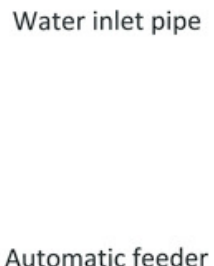

Recorder antenna

\& opening

Inaccessible area

Water outflow

Air stone

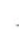
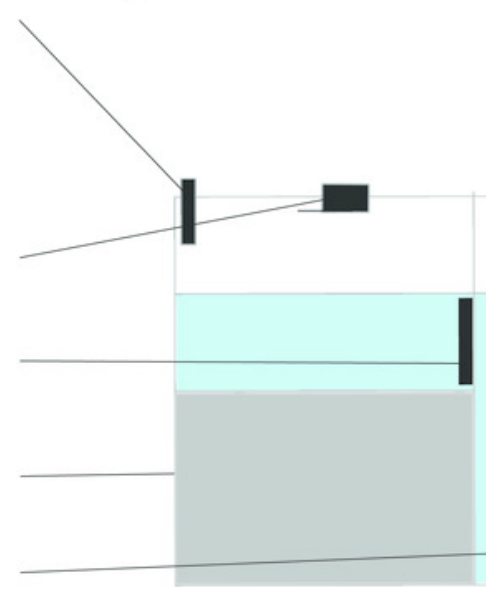

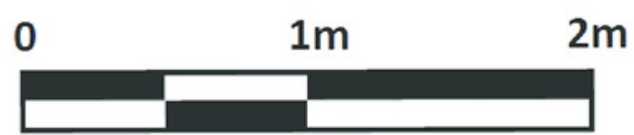




\section{Figure 3 (on next page)}

The mean ( $\pm 1 \mathrm{SE}$ ) number of entries into the rewarded and unrewarded room for low stress and high stress mulloway over time. 


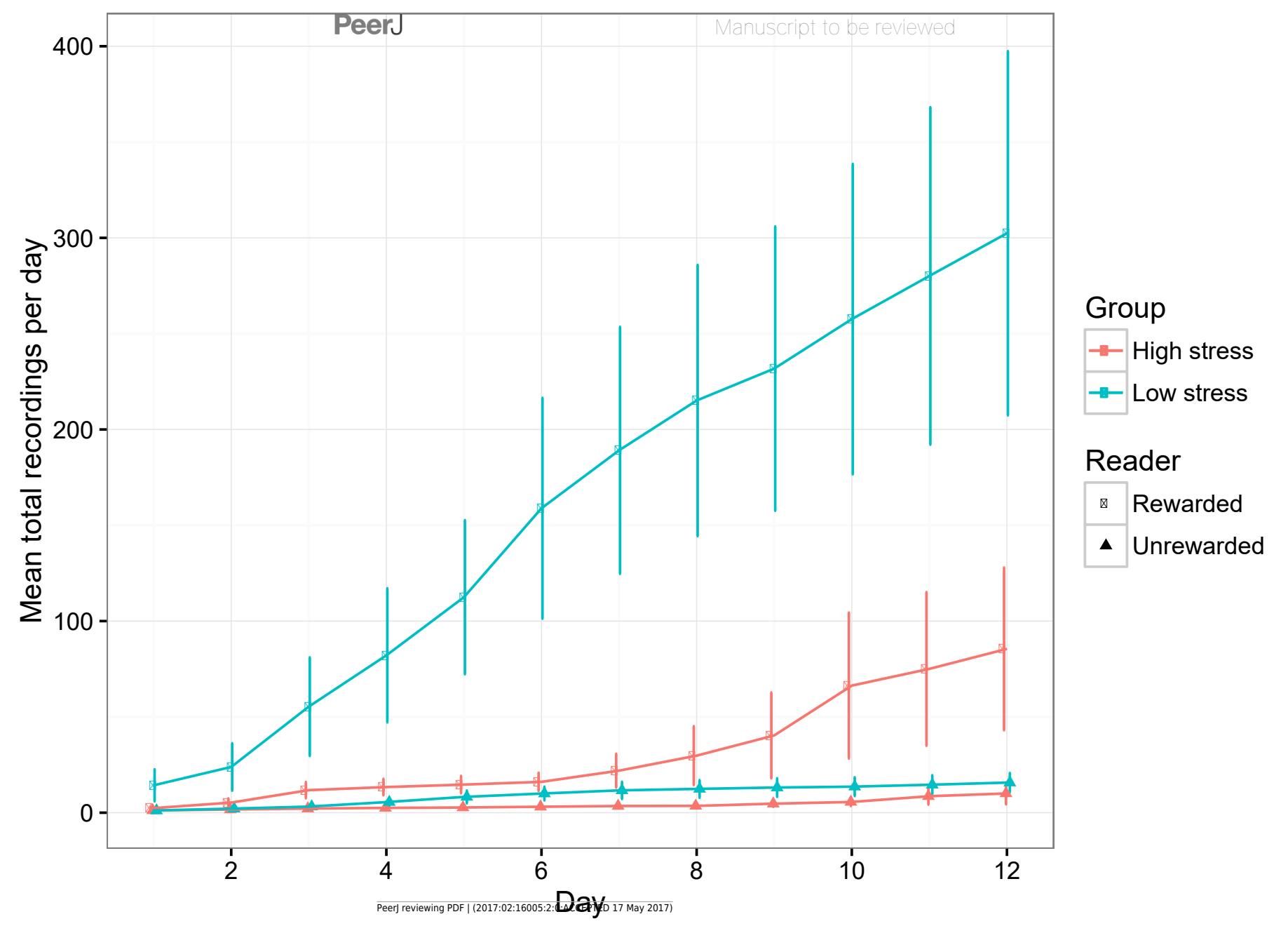


Figure 4 (on next page)

Mean ( $\pm 1 \mathrm{SE}$ ) logit-transformed preference for the rewarded compartment in low stress and high stress mulloway over time.

Preference for the rewarded compartment over the unrewarded compartment was used as a proxy for learning in this experimental setup: preference for the rewarded compartment was expected to increase over time as fish learned that food was available in only one of the two compartments. Here, a logit value of 0 indicates no preference for either compartment, and logit values above that indicate greater preference for the rewarded compartment. A logit of 4.5 represents near $\sim 100 \%$ preference for the rewarded compartment. 


\section{Table $\mathbf{1}$ (on next page)}

Summary of generalized linear model of recordings per day into the rewarded and unrewarded compartments for low stress and high stress responding fish. 
Table 1: Summary of generalized linear model of recordings per day

\begin{tabular}{|l|l|l|l|l|}
\hline Factor & Estimate & Standard error & t value & P value \\
\hline Day & 0.14 & 0.02 & 6.44 & $<0.001$ \\
\hline Stress type & 0.32 & 0.23 & 1.42 & 0.16 \\
\hline Compartment & -1.68 & 0.11 & -15.88 & $<0.001$ \\
\hline Stress type * Day & 0.09 & 0.03 & 2.94 & $<0.01$ \\
\hline
\end{tabular}

2 


\section{Table 2(on next page)}

Generalized linear model of preference for the rewarded over the unrewarded compartment between low stress and high stress responding fish during the experiment. 
1 Table 2: Generalized linear model of preference for the reward compartment

\begin{tabular}{|l|l|l|l|l|}
\hline Factors & Estimate & Std. Error & T value & P value \\
\hline Day & 0.12 & 0.03 & 4.25 & $<0.001$ \\
\hline Stress type & 1.18 & 0.20 & 5.85 & $<0.001$ \\
\hline
\end{tabular}

2 